\title{
Association of papillary thyroid cancer with thyroid autoimmunity
}

\section{Gesthimani Mintziori, Fotini Adamidou, Zoe Efstathiadou, Athanasios Panagiotou, Panagiotis Anagnostis, Marina Kita}

Department of Endocrinology, Diabetes and Metabolism, Hippokrateion General Hospital, Thessaloniki, Greece

\section{Introduction}

Although the association between thyroid autoimmunity and papillary thyroid carcinoma (PTC) is supported by clinical studies, evidence to their pathophysiologic link and causal relationship is lacking. Moreover, there is a paucity of data regarding the association of thyroid autoimmunity with the less common types of differentiated thyroid cancer (DTC).

The aim of the current paper was to investigate the association of autoimmunity and PTC versus follicular or medullary thyroid cancer.

\section{Methods}

We conducted a retrospective, registry-based study in the Department of Endocrinology, Ippokratio General Hospital, Thessaloniki, Greece.

Inclusion criteria:

Patients with histologic evidence of DTC that were pre-operatively screened for thyroid autoimmunity were included in the study.

\section{Exclusion criteria:}

Patients with known cancer-related syndromes (patients with autoimmune polyglandular syndrome or multiple endocrine neoplasia) were excuded from the analysis.

Duration of the study:

5 years $(2009-2014)$
Table 1. Demographic data and clinical characteristics of the patients at the time of thyroid cancer diagnosis

\begin{tabular}{|c|c|c|c|c|}
\hline $\begin{array}{l}\text { Demographic data } \\
\text { and clinical } \\
\text { characteristics at } \\
\text { the time of thyroid } \\
\text { cancer diagnosis }\end{array}$ & $\begin{array}{l}\text { Patients with PTC } \\
N=54\end{array}$ & $\begin{array}{l}\text { Patients with FTC } \\
N=6\end{array}$ & $\begin{array}{l}\text { Patients with MTC } \\
N=5\end{array}$ & $\begin{array}{l}\text { In total } \\
N=65\end{array}$ \\
\hline Age & $51 \pm 2$ & $46 \pm 6$ & $59 \pm 7$ & $51 \pm 2$ \\
\hline $\begin{array}{l}\text { Thyroid autoimmunity } \\
\text { [n (\%)] }\end{array}$ & $23(43)$ * & $0(0)^{*}$ & $1(20)^{*}$ & $24(37)$ \\
\hline $\mathrm{TSH}(\mu \mathrm{l} \mathrm{U} / \mathrm{mL})$ & $2(3,25)$ & $3(2,75)$ & $2(1,5)$ & $2(1,75)$ \\
\hline
\end{tabular}

Data are presented as mean \pm SD or, in case of non-parametric data as median (interquartile range)

$\mathrm{p}<0,05$

PTC: papillary thyroid carcinoma, FTC: follicular thyroid carcinoma , MTC: medullary thyroid carcinoma

Thyroid autoimmunity was defined as presence of positive anti-TPO and/or anti-Tg antibodies. Statistical analysis was performed with the use of IBM SPSS 20.

\section{Results}

Sixty-five patients with thyroid cancer were assessed (12 men and 53 women). Their mean age was $51 \pm 2$ years. Out of 65 patients, 54 patients had PTC, 6 had follicular cancer and 5 patients had medullary cancer.

When patients with PTC were compared with patients with follicular or medullary cancer, the prevalence of thyroid autoimmunity was higher in patients with PTC in comparison with patients with other types of thyroid cancer ( $43 \%$ vs. $9 \%$ respectively, $\mathrm{p}=0.035$ ), independently of TSH concentrations (Table 1).

\section{Conclusion}

This small retrospective study demonstrates that patients with PTC demonstrate significantly higher prevalence of thyroid autoimmunity, in comparison with other types of DTC. This observation suggests that a biological link exists preferentially between thyroid autoimmunity and PTC.

Further study into this differential association may provide insights for better prevention and management of PTC.

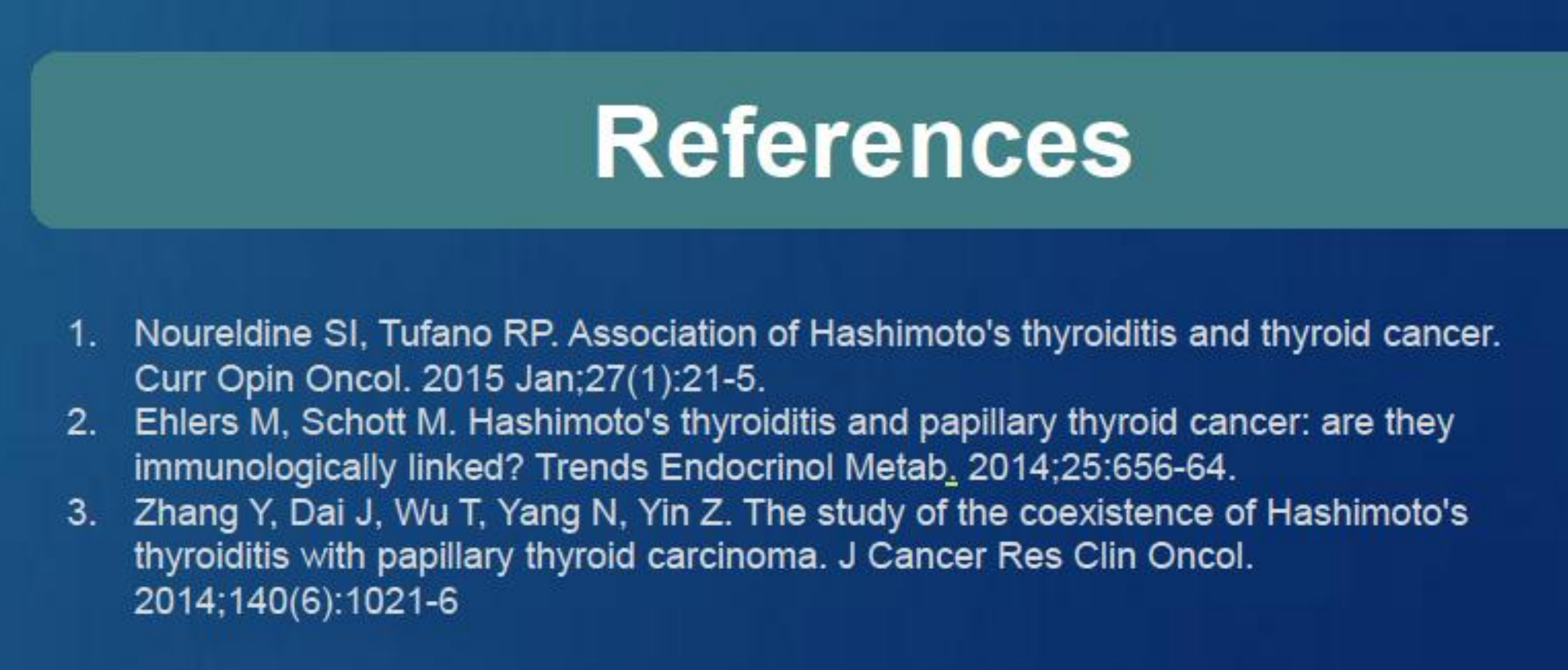

